\title{
Adolescent Health; A Must Priority
}

Tara Ballav Adhikari

\begin{abstract}
Adolescence is the period of physical, psychological and social maturing from childhood to adulthood. Generally, the term "adolescents" refers to individuals between the ages of 10-19 years and the term "youth" refers to individuals between the ages of 15-24 years, while "young people" covers the entire age range, from ages 10-24 years (WHO/ UNFPA/UNICEF, 1989).
\end{abstract}

According to 2001 census in Nepal, there are approximately 5.4 million (23.6\%) adolescent population in Nepal, and upcoming census 2011 is likely to show the same trend because of the fact that the fertility rate has moved a little during the period and huge childhood population is entering the adolescent age. Adolescent population is expected to increase 6 million by the year 2011 and to almost 7 million in 2021.

Adolescents complete their physical, emotional and psychological journey to adulthood in a changing world that contains both opportunities and dangers. Most adolescents are full of optimism and represent a positive force in society, an asset now and for the future as they grow and develop into adults. When supported, they can be resilient in absorbing setbacks and overcoming problems. However, adolescents are exposed to risks and pressures on a scale that their parents did not face. Globalization has accelerated change while the structures that protected previous generations of young people are being eroded. Adolescents receive contradictory messages on how to address the daily choices which have lifelong consequences for healthy development. Millions are denied the essential support they need to become knowledgeable, confident and skilled adults. They miss out on schooling for economic reasons or because their communities are displaced or disrupted by war or conflict.And, while most young people have loving families who protect and care for them, many grow up with no adults committed to their welfare or where the ability of caring adults to support them has been damaged. Adolescents are at risk of early and unwanted pregnancy, of sexually transmitted infections (STIs) including HIV and AIDS, and vulnerable to the dangers of tobacco use, alcohol and other drugs. In Nepal, 64\% of adolescent already has Sexual intercourse between 1517 years age and the Mean age of sexual intercourse in male is 16.4 year and it is 16 year in female.

In Nepal $23.3 \%$ adolescent are illiterate (2001 census).literacy rate of adolescent in Nepal has been increased as compared to1991 level but there is still vast difference of literacy rate between boys and girls. School dropouts are relatively higher among girls than boys. There are many factors for the differences in boys and girls education level; parents preference, economic reasons early marriage, girls gender roles on domestic chores and to look after siblings ,cultural restricts on mobility of daughter, inaccessible of school etc are some of main factors to cause this difference. NDHS 2006 found that $92 \%$ of adolescent girls aged 15-19 and 60 percent of adolescent boys of same age group were engaged in agriculture sector. Only $1.6 \%$ of adolescent girls and $2.6 \%$ adolescent boys were engaged in professional /technical /managerial area. And $23 \%$ of all laborers are of age 10-14 years.

Many are exposed to violence and fear on a daily basis. Some of the pressures adolescents are under, or the choices they make, can change the course of their young lives, or even end them. These outcomes represent personal tragedies for young people and their families. They are also unacceptable losses that put the health and prosperity of society at risk. Addressing the needs of adolescents is a challenge that goes well beyond the role of health services alone. The legal framework, social policy, the safety of communities and opportunities for education and recreation are just some of the factors of civil society that are key to adolescent development. However, within an integrated approach, health services can play an important role in helping adolescents to stay healthy and to complete their journey to adulthood; supporting young people who are looking for a route to good health, treating those who are ill, injured or troubled and reaching out to those who are at risk.

'Adolescent friendly' health services meet the needs of young people in this age range sensitively and effectively and are inclusive of all adolescents. Such services deliver on the rights of young people and represent an efficient use of precious health resources. Effective health services reach adolescents who are growing up in difficult circumstances as well as those who are well protected by their communities. Health services need to link with the other key services for adolescents, so that they become part of a supportive structure that protects young people against dangers, and helps them to build knowledge, skills and confidence.

This is far from being the case in many countries. Health services often regard adolescents as a healthy group who do not need priority action, and so provide a minimum subset of adult or pediatric services with no adjustments for their special needs.

There is evidence that many young people regard such 
health services as irrelevant to their needs and distrust them. They avoid such services altogether, or seek help from them only when they are desperate.

This adolescent period is vulnerable period due to absence of proper guidance and counseling. Family has a crucial role in shaping the adolescents behavior. They have to insure a safe secure and supportive environment for the adolescent's.Family members in the community to be informed and educated about the problem. A positive and encouraging attitude has to be developed among the family members and the parents .School teachers should be trained on adolescent heath. Community leaders and government should also play a vital role on adolescent health care.

Providing health education in regard to sexual change, sexuality and gender helps to reduce the stigma and misconception associated with health problems and services. Involving adolescent in developmental and decision making activities increases adolescent utilization of health care services and also the ownership of program by them. Sensitization of parents, teachers and social leader on the need and issue of adolescent health and establishing the linkages between health facilities and adolescent club helps to increase the young's participation to the health and developmental activities and also to health service utilization.

\section{References}

1. Ministry of Health and population,Annual report 206566, Departement of health service Teku Kathmandu Nepal

2. Nepal Demographic and Health survey, Ministry of Health and population (Nepal), NEW ERA. 2006

3. Shestha R D. Reproductive health: National and international perspective. Kathmandu Nepal: New Dhulikhel Printing press; 2008 